OPEN ACCESS

Edited by:

Yiqiang Zhan,

Karolinska Institute (KI), Sweden

Reviewed by:

James Harper,

Sam Houston State University,

United States

Yong Mao,

Kunming Medical University, China

*Correspondence:

Livio Provenzi

livio.provenzi@bp.Inf.it

Specialty section:

This article was submitted to Endocrinology of Aging,

a section of the journal

Frontiers in Endocrinology

Received: 28 July 2017 Accepted: 16 October 2017 Published: 31 October 2017

Citation:

Provenzi L, Scotto di Minico G, Giorda $R$ and Montirosso R (2017) Telomere Length in Preterm Infants:

A Promising Biomarker of Early Adversity and Care in the Neonatal Intensive Care Unit?

Front. Endocrinol. 8:295. doi: 10.3389/fendo.2017.00295

\section{Telomere Length in Preterm Infants: A Promising Biomarker of Early Adversity and Care in the Neonatal Intensive Care Unit?}

\author{
Livio Provenzi' ${ }^{1 *}$, Giunia Scotto di Minico ${ }^{1}$, Roberto Giorda ${ }^{2}$ and Rosario Montirosso ${ }^{1}$ \\ '0-3 Center for the At-Risk Infant, Scientific Institute IRCCS Eugenio Medea, Lecco, Italy, ${ }^{2}$ Molecular Biology Laboratory, \\ Scientific Institute, IRCCS Eugenio Medea, Lecco, Italy
}

Preterm infants present an immature neurobehavioral profile at birth, even in absence of severe brain injuries and perinatal complications. As such, they require a long-lasting hospitalization in the Neonatal Intensive Care Unit (NICU), which is thought to grant at-risk newborns' survival, but still entails a number of physical, painful, and socio-emotional stressors. Hence, preterm birth and NICU stay represent an early adverse experience, which has been linked to detrimental consequences for neurological, neuro-endocrinal, behavioral, and socio-emotional development, as well as to disease later in life. Recent advances in the behavioral epigenetic field are helping us to unveil the potential mechanisms through which early NICU-related stress may lead to negative developmental outcomes. From this perspective, telomere regulation might be a key programming mechanism. Telomeres are the terminal portion of chromosomes and are known to get shorter with age. Moreover, telomere length $(T L)$ is affected by the exposure to stress during early development. As such, TL might be an innovative biomarker of early adverse exposures in young infants and children. Unfortunately, there is paucity of studies investigating TL in populations of preterm infants and its association with known NICU-related stressors remains unexplored. In the present paper, the potential relevance of TL for research and clinical work with preterm infants will be underlined in the light of recent contributions linking progressive telomere shortening and early exposure to adverse experiences and stressful environments in humans. Finally, insights will be provided to guide clinically relevant translational research on TL in the field of VPT birth and NICU stay.

Keywords: adversity, epigenetics, neonatal intensive care unit, pain, preterm birth, stress, telomere

\section{INTRODUCTION}

Preterm birth ( $<37$ weeks of gestational age) is estimated to account for about $11 \%$ of all live births worldwide (1). During the last decades, biomedical progress has greatly improved the survival rates of prematurely born infants. Notwithstanding, preterm birth still constitutes a major health problem worldwide (2). Notably, despite preterm infants' morbidity is highly affected by the extent of brain damage and immaturity and other related clinical conditions, preterm infants' health and disease is at least partially affected by the stressful nature of the precocious hospitalization in the Neonatal Intensive Care Unit (NICU) (3). 
Telomeres are repeat sequences at the ends of chromosome arms, known to shorten because of cellular aging and in relation to disease conditions (4). Recent studies highlighted that stress greatly influences telomere erosion by shaping the biochemical structure in ways that may promote telomere damage, inflammation, and greater rate of leukocyte division, in part through the impairment of telomerase-mediated elongation, but also through other pathways $(5,6)$. Unfortunately, the effects of early stress exposure on telomere length (TL) in hospitalized preterm infants remain unexplored. Here, we discuss how TL might be an emergent research field with potential innovative insights for researchers and clinicians involved in the neonatal care of preterm infants.

\section{PRETERM BIRTH AND NICU STAY AS AN EARLY ADVERSE EXPERIENCE}

Preterm infants need long-term hospitalization and specialized multi-disciplinary interventions in NICU. During this time, they are exposed to painful procedures $(7,8)$ and high-intensity physical stimulation (e.g., lights and sounds exposure) which represent sources of stress affecting the development of the brain and of the neuroendocrine system $(9,10)$. As a result, preterm birth is associated with heightened risk of long-term detrimental consequences for development, including sensorial, behavioral, neurological, and emotional disorders $(11,12)$. Even in absence of critical comorbidities, NICU procedures are distressful for premature newborns, leading to long-lasting programming of less-than-optimal developmental trajectories (13-15).

\section{Sources of NICU-Related Stress}

The NICU environment is far from being a surrogate of the maternal womb and represents a source of distress in newborns due to three main aspects: (1) sensorial adverse stimulation, (2) invasive and painful procedures, and (3) limited opportunities for parental caregiving and alteration of parent-infant bonding.

First, infants are exposed to physical and sensorial stimulations (i.e., lights and sounds) characterized by levels of intensity and length of exposure which easily exceed the average recommended exposure standard for newborns (10). As such, NICU sensory conditions contribute to physiological instability in preterm infants, causing long-term harmful consequences for visual and auditory development later in life (16).

Additionally, invasive and painful clinical procedures (e.g., intubations, venipunctures, arterial insertions, and surgery) are needed to improve the health status of preterm infants. Due to their immature neurobehavioral profile, preterm infants present lower threshold and higher sensitization to external perturbations, so that even routine handling (e.g., diaper change) might be responded to with a heightened physiological response (17). Interventions such as skin-breaking procedures have been associated with detrimental consequences for shortand long-term development $(18,19)$, encompassing structural and functional alterations of brain development, which persist throughout childhood (20). Furthermore, the level of NICUrelated pain exposure is associated with neurodevelopment, including motor and cognitive development (21) as well as emotional problems during later childhood (22). These developmental alterations are partially mediated by an altered functioning of the main system of stress response, namely the hypothalamic-pituitary-adrenal (HPA) axis. Several studies documented that cumulative exposure to skin-breaking pain during NICU stay might associate with altered resting cortisol levels (15), increased stress reactivity (13), and altered HPA regulation (23) in prematurely born subjects, independently from clinical confounders.

Notably, preterm newborns are suddenly separated from the mother after birth, which may disrupt the biological routes to caregiving and parental bonding (24) and alter HPA axis reactivity to pain stimulations (25).

\section{NICU Stay and Developmental Care (DC)}

During the last decades, DC strategies have been developed to minimize the negative effects of preterm birth, optimize infants' neurobehavioral development, and improve interactions between parents and infants $(26,27)$. DC includes the management and reduction of external stimuli (e.g., vestibular, auditory, visual, tactile), the facilitation of parental presence, and involvement in early care of the infant (e.g., kangaroo care, a technique in which infants are placed in skin-to-skin contact with a parent, usually on the breast), the facilitation of breastfeeding, and pain management (e.g., non-pharmacological analgesia such as non-nutritive sucking, glucose, containment with towels or blankets) (28). These interventions are meant to promote parent-to-infant bonding and to promote better outcomes in terms of infants' neurobehavioral stability (e.g., nesting, swaddling, prone positioning).

The quality of DC is critical to counterbalance the effect of NICU-related stressors on preterm infants' developmental trajectories. Preterm infants hospitalized in NICUs characterized by high quality of DC practices exhibit better neurobehavioral development during the first month of life (29), less internalizing behaviors at 18 months (30), and improved language outcomes at 36 months (31). Specific DC interventions, such as kangaroo care, are associated with improved physiologic stability (32), sleep organization (33), brain maturation (34), and behavioralemotional development (35).

\section{PRETERM BEHAVIORAL EPIGENETICS: IN SEARCH OF BIOLOGICAL MECHANISMS}

Despite NICU-related stress has well-known impact on preterm infants' development, little is known about the underlying biological mechanisms. Recent scientific advances suggest that epigenetic mechanisms are highly sensitive to environmental stimulations and might play a pivotal role in the embedding of early NICU-related adversities into the developing trajectories of preterm infants. DNA methylation of stress-related genes [e.g., NR3C1, encoding for cortisol receptors and SLC6A4, encoding for the serotonin transporter (36)] is affected by NICU-related pain exposure $(37,38)$. Moreover, these epigenetic markers have been linked with long-lasting developmental trajectories in behavioral and socio-emotional domains during infancy $(39,40)$ and childhood (37). 
Notwithstanding, epigenetic mechanisms include a wide set of biochemical DNA modifications other than DNA methylation and telomere shortening represents another potential mechanism that has received limited attention in the field of prematurity. Here, we provide a perspective on the possibility that the NICU-related stress might exert stress-dependent telomere erosion.

\section{TL as a Cellular Aging Biomarker}

Telomeres are the DNA-protein structures capping each chromosome end, regulated by the enzyme telomerase (41). With each cell replication, telomeres shorten until they reach a certain limit, after which the cell enters a state of arrest (Figure 1). Notably, TL depends on (a) its initial setting at birth and (b) the magnitude of telomere erosion from birth onward (42). Telomere erosion, in turn, depends on cell replication rate, cumulative exposure to agents that produce DNA damage (such as oxidative, inflammatory, endocrine, and other forms of biological stress), and activity of the telomerase enzyme (43). Shortened TL and/or reduced telomerase activity have been associated with health risk and diseases (44-46).

\section{TL as an Early Adversity Exposure}

Telomere length regulation and telomerase activity are influenced by environmental and behavioral factors (6). Animal studies documented that manipulation of maternal diet during pregnancy has an effect on offspring TL among different tissues and organs (47). In chickens, prenatal administration of corticosteroids in the yolk resulted in greater telomere erosion and increased duration of stress response in the offspring compared to a control group (48).

Human studies also documented associations between telomere regulation and high levels of psychosocial stress exposure (49-51), suggesting that stress-related changes in telomere integrity may be one possible mechanism linking psychosocial stress and age-related disease (52). Entringer and colleagues (53) recently reported an association between maternal exposure to severe psychosocial stress during pregnancy and TL of children during young adulthood. Moreover, pregnancy-related maternal stress predicted shorter newborn leukocyte TL (5). Additionally, many studies found that exposure to adverse conditions in early
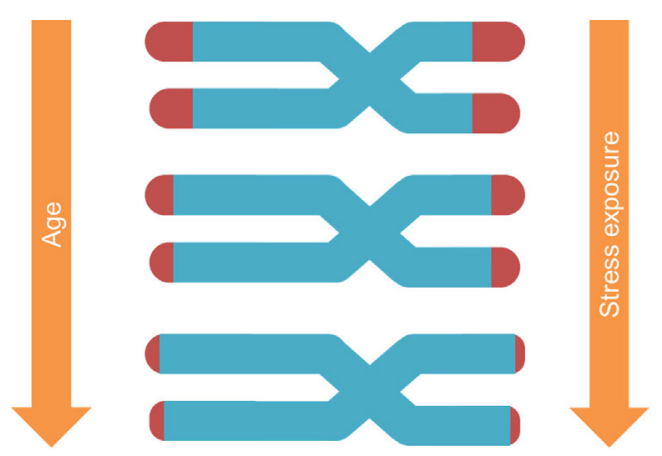

FIGURE 1 | Telomere shortening is affected both by age and stress exposure. postnatal life such as severe social deprivation (54), maltreatment $(55,56)$, and PTSD $(57)$ is associated with subsequent shortening of telomeres.

\section{IMPLICATIONS OF TL FOR PRETERM INFANTS STRESS AND DC}

In light of the evidence reported above, analysis of TL can be a technique that might reveal scientifically intriguing and clinically relevant insights into early developmental risk detection and to better predict developmental outcomes of preterm infants. Based on the literature reviewed, one might hypothesize that preterm infants might present a pronounced risk of early telomere erosion. Specifically, in the next sections, we provide an overview of (1) current evidence pertaining to TL analysis and prematurity; (2) methodological issues; and (3) implications for research and clinical practice.

\section{TL Analysis and Prematurity: Current Evidence}

To best of our knowledge, only few studies have investigated TL in the preterm infants. One study reported no significant differences between mean leukocyte TLs of preterm infants compared with their full-term counterparts at birth (58). However, very low birth weight preterm infants $(<1,500 \mathrm{~g})$ had significantly longer telomeres than low birth weight ones $(1,500-2,500 \mathrm{~g})$, and gestational age appeared to be a significant mediator of telomere restriction. Moreover, this study was cross-sectional, 15 preterm and 11 full-term newborns were included and no longitudinal evidence of telomere erosion was provided. In a subsequent prospective study, five preterm infants and eight age-matched fetuses were followed longitudinally for 8-12 weeks and consistent telomere erosion was observed in preterm infants between 23 and 35 weeks of gestation (59). In a larger sample study, Menon and colleagues (60) compared TLs of infants following either spontaneous preterm birth with intact membrane, or preterm birth due to premature rupture of membrane (pPROM) and fullterm infants. In intact-membrane pregnancies, fetal leukocyte TL was inversely proportional to gestational age. Moreover, newborns from intact-membrane gestations had longer telomeres compared to both full-term infants and preterm infants following $\mathrm{pPROM}$.

In a more recent longitudinal study, TL was assessed at birth in both preterm and full-term infants and at term-equivalent age in preterms only (61). Preterm infants were found to have longer telomeres compared to full-term counterparts. Nonetheless, consistent with previous research $(58,60)$, TL erosion increased with advancing gestational age at birth in a limited subgroup of infants $(N=5)$. Vasu and colleagues $(61)$ concluded that the longer telomeres measured in the preterm infants' sample at birth might be due to a period of high cell turnover and replicative stress which occurs during the final weeks of pregnancy for fullterm infants, but not for prematurely born ones. Despite current results are non-conclusive and further research is needed, this evidence suggests that altered TL regulation might play a role in preterm infants' status. 


\section{Methodological Issues}

Previous TL research in preterm infants mainly focused on birth and/or term-equivalent age. Moreover, as reported by Vasu and colleagues (61), the samples of previous works are relatively small so that the studies might be underpowered with limited capacity to detect true associations between prematurity-related conditions and telomere erosion. In addition, to date, no study has inquired the effects of NICU-related stress and DC practices on telomere regulation in preterm infants. In the following sections, we review specific issues implied by research on TL in preterm infants and provide insights for future research.

A major issue in measuring TL is the availability of many methods to assess telomere erosion (62) such as TRF analysis, quantitative RT-PCT, single telomere length analysis (STELA), and quantitative FISH (Q-FISH). To the best of our knowledge, there is no rationale for choosing one as a gold standard as each method presents different strengths and limitations. They vary in terms of training needed and equipment costs (low in TRF and high in Q-FISH and quantitative RT-PC), risk of artifacts and variability (e.g., slot blot analysis has limited risk of artifacts, but provides highly variable data, particularly with small samples), and capacity to provide TL information on global DNA (e.g., quantitative RT-PCR) or single chromosomes (e.g., STELA). As such, the choice of method should take into consideration all these aspects as well as the aims of the research study. Notably, the presence of studies using diverse techniques require relevant efforts to replicate these findings in future research (62).

Another critical point is that preterm infants constitute a heterogeneous population, varying on perinatal (e.g., birth weight, gestational age, clinical complications, etc.), socio-demographic (e.g., socio-economic status), and contextual factors (e.g., NICU quality of DC). This implies that researchers need to pay attention to different conditions that interact in a complex manner in affecting TL in preterm infants. For instance, preterm infants born at lower gestational age might have longer telomeres at birth but greater stress-related erosion due to cumulative NICUrelated stress and pain. Consistently, careful selections of preterm infants in terms of inclusion criteria should be pursued to avoid mixed samples of subjects, which might affect the quality of life, developmental trajectories, and number of stressful intervention to which they are exposed during the NICU stay.

Differences in DC practices among diverse NICUs and countries represent another source of variation (63). Despite the lack of information on epigenetic effects associated with DC (64), different levels of care are known to be related to different developmental outcomes (65). Future research should take into account the existence of differences in DC quality when investigating telomere regulation in preterm infants, possibly using a multi-centric study design involving different NICUs.

Finally, the context and timing of early adversity exposure might be critical in setting a TL-related biomarker of later-in-life health and disease $(5,66)$. As such, longitudinal and prospective research designs should be considered the golden standard when looking at epigenetic variations and TL. The model of preterm newborns and infants constitutes a naturally occurring condition in which stress exposure is expected and thus can be measured and monitored at different time points through different epigenetic biomarkers (67).

\section{Implications for Research and Clinical Practice}

Figure 2 reports major areas of future investigations in this field. First, as previous research on animal models (68) and human adults (66) documented that stress is highly involved in increased

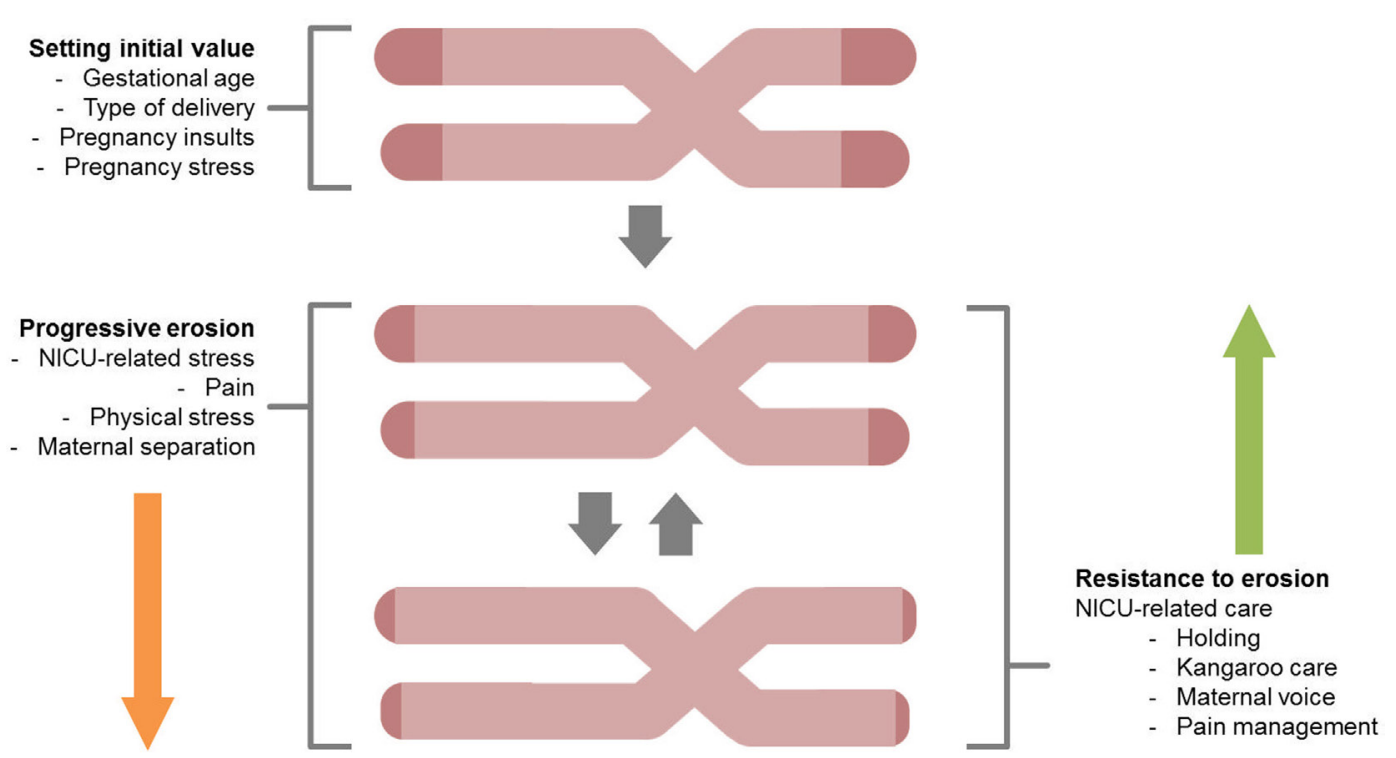

FIGURE 2 | A schematic overview for the study of telomere length shortening in preterm infants. Both stressful effects (progressive erosion) and protective factors (resistance to erosion) are highlighted. 
Previous literature evidence: Telomere erosion as an adversity biomarker and a programming agent

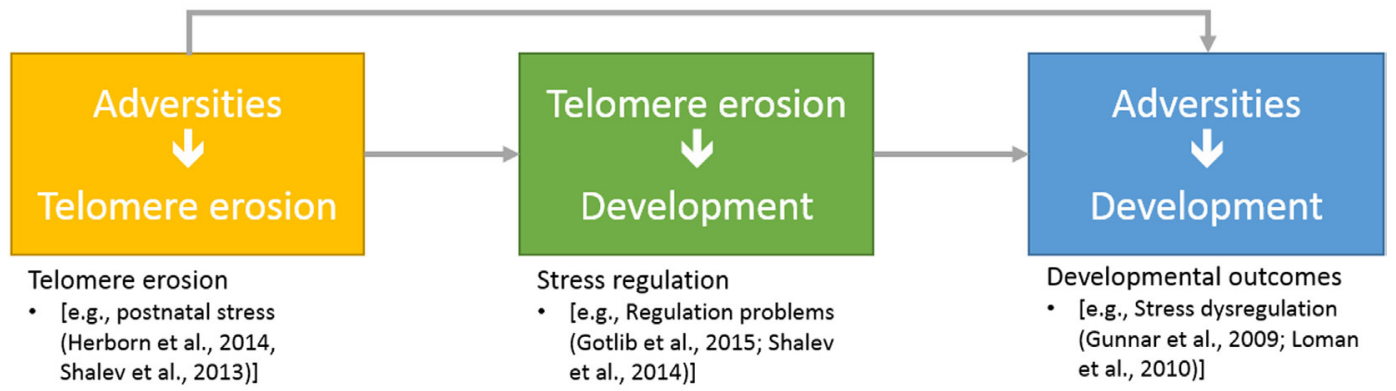

Application to the preterm infant model: A call to action for clinically-relevant research

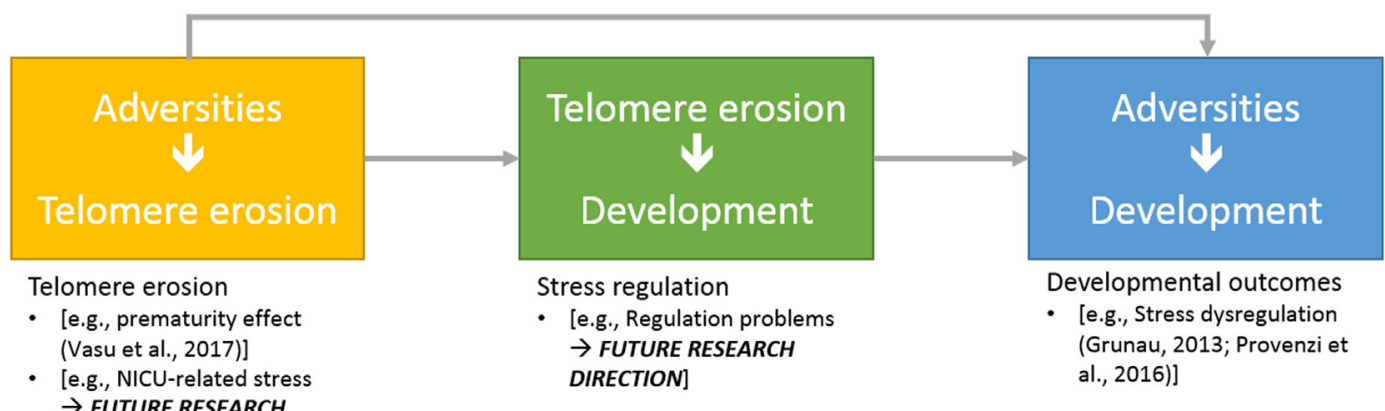

DIRECTION]

FIGURE 3 | Schematic overview of potential research directions on telomere length erosion in preterm infants: (a) effects of NICU-related adversities on telomere erosion; (b) the predictive role of telomere erosion on developmental outcomes.

erosion of telomeres, one might wonder whether NICU-related stress has an impact on preterm infants' TL from birth to discharge. Notably, a key component of NICU-related stress is represented by invasive and painful stimulations [e.g., skin-breaking procedures and invasive mechanical ventilation (7)]. Cumulative pain exposure in NICU has epigenetic effects on stress-related genes $(38,69)$. A direct link between pain and telomere regulation in humans has been found in patients with osteoarthritis: those with high levels of pain had shorter telomeres compared to the counterparts reporting low pain (70). Moreover, preterm infants are at risk for HPA axis dysregulation (23). Notably, children exposed to early adverse experiences (i.e., maternal depression) not only exhibit shorter telomeres compared to controls but increased TL erosion was associated with heightened HPA axis reactivity to a stress-inducing laboratory procedure (71). Consistently, direct investigation of the association among NICU levels of pain exposure (e.g., number of skin-breaking procedures), rate of TL shortening and the HPA axis dysregulation represent an interesting path for future research (see Figure 3).

Future investigation could also consider the protective effects of DC practices in reducing or slowing the rate of telomere erosion. Studies in adult human subjects have demonstrated that positive changes in life-style have the possibility to result in significantly increased telomerase activity and improved telomere maintenance capacity in human immune-system cells (72). Similarly, one could hypothesize that positive changes in the NICU, in term of healing environment (e.g., reduction of sensorial adverse stimulation), infant pain management, increased presence of parents, facilitation of early interaction and parent-infant bonding, might result in a relenting of telomere erosion in preterm infants.

\section{CONCLUSION}

The study of TL in preterm infants is an intriguing area of research and a potential source of scientifically sound beneficial information for NICU staff. Although now it remains a hypothetical scenario, it is possible to speculate that TL measure might have some clinical implications for NICU-related stress and infant DC. For example, given the evidence for association between TL and pain (70), one could expect that TL might be used as a marker of the effect of pain exposure in preterm infants. It is also intriguing to hypothesize that TL could be used to document the biological correlates (by either decreasing the erosion rate or improving the turnover of telomerase activity) of the beneficial effects of DC practices, such as kangaroo care and infant/caregiver closeness. From this perspective, the investigation of the 
role of early environment in affecting TL regulation dynamics is warranted to be a pivotal area of research in future preterm infants' research, especially within the emergent area of preterm behavioral epigenetics field of study (36). In sum, despite the field of preterm behavioral epigenetics is still at its beginning (73), TL could become a biomarker of developmental risk in both high- and low-risk preterm infants, holding promises of providing NICU staff with innovative index to predict which infants are at increased risk of less-than-optimal developmental outcomes.

\section{AUTHOR CONTRIBUTIONS}

LP conceived the work, wrote the first draft of the manuscript, and approved the final version of the paper. GSM contributed to literature review, revised English language, and approved the final version of the paper. RG supervised the work, by providing unique expertise in relation to biological sections, and he approved the

\section{REFERENCES}

1. Blencowe H, Cousens S, Chou D, Oestergaard M, Say L, Moller A-B, et al. Born too soon: the global epidemiology of 15 million preterm births. Reprod Health (2013) 10:S2. doi:10.1186/1742-4755-10-S1-S2

2. Montagna A, Nosarti C. Socio-emotional development following very preterm birth: pathways to psychopathology. Front Psychol (2016) 7:80. doi:10.3389/fpsyg.2016.00080

3. Horbar JD, Edwards EM, Greenberg LT, Morrow KA, Soll RF, Buus-Frank ME, et al. Variation in performance of neonatal intensive care units in the United States. JAMA Pediatr (2017) 171:e164396. doi:10.1001/jamapediatrics. 2016.4396

4. Lindqvist D, Epel ES, Mellon SH, Penninx BW, Révész D, Verhoeven JE, et al. Psychiatric disorders and leukocyte telomere length: underlying mechanisms linking mental illness with cellular aging. Neurosci Biobehav Rev (2015) 55:333-64. doi:10.1016/j.neubiorev.2015.05.007

5. Entringer S, Epel ES, Lin J, Buss C, Shahbaba B, Blackburn EH, et al. Maternal psychosocial stress during pregnancy is associated with newborn leukocyte telomere length. Am J Obstet Gynecol (2013) 208:134.e1-7. doi:10.1016/j. ajog.2012.11.033

6. Shalev I, Entringer S, Wadhwa PD, Wolkowitz OM, Puterman E, Lin J, et al. Stress and telomere biology: a lifespan perspective. Psychoneuroendocrinology (2013) 38:1835-42. doi:10.1016/j.psyneuen.2013.03.010

7. Grunau RE. Neonatal pain in very preterm infants: long-term effects on brain, neurodevelopment and pain reactivity. Rambam Maimonides Med J (2013) 4:e0025. doi:10.5041/RMMJ.10132

8. Valeri BO, Holsti L, Linhares MB. Neonatal pain and developmental outcomes in children born preterm. Clin J Pain (2014) 31(4):355-62. doi:10.1097/ AJP.0000000000000114

9. Brown G. NICU noise and the preterm infant. Neonatal Netw (2009) 28:165-73. doi:10.1891/0730-0832.28.3.165

10. Ozawa M, Sasaki M, Kanda K. Effect of procedure light on the physiological responses of preterm infants. Jpn JNurs Sci (2010) 7:76-83. doi:10.1111/j.1742-7924.2010.00142.x

11. Saigal S, Day KL, Van Lieshout RJ, Schmidt LA, Morrison KM, Boyle MH. Health, wealth, social integration, and sexuality of extremely low-birth-weight prematurely born adults in the fourth decade of life. JAMA Pediatr (2016) 170:678. doi:10.1001/jamapediatrics.2016.0289

12. Stoll BJ, Hansen NI, Bell EF, Shankaran S, Laptook AR, Walsh MC, et al. Neonatal outcomes of extremely preterm infants from the NICHD neonatal research network. Pediatrics (2010) 126:443-56. doi:10.1542/ peds.2009-2959

13. Holsti L, Grunau RE, Oberlander TF, Whitfield MF. Prior pain induces heightened motor responses during clustered care in preterm infants in the NICU. Early Hum Dev (2005) 81:293-302. doi:10.1016/j.earlhumdev.2004.08.002 final version of the paper. RM contributed to the conception of the work, supervised the writing, and approved the final version of the paper. All authors agree to be accountable for all aspects of the work.

\section{ACKNOWLEDGMENTS}

The authors wish to thank Patrizia De Salvo, Lorenzo Giusti, and Eleonora Visintin, colleagues at the 0-3 Center for the at-Risk Infant. Special thanks go to Renato Borgatti for his precious advice and supervising role.

\section{FUNDING}

The writing of the present manuscript has been supported by funds from the Italian Health Ministry for a research assessing the role of genetic and epigenetic factors in early development of very preterm infants (RC 01/05 2015-2017).

14. Vinall J, Miller SP, Chau V, Brummelte S, Synnes AR, Grunau RE. Neonatal pain in relation to postnatal growth in infants born very preterm. Pain (2012) 153:1374-81. doi:10.1016/j.pain.2012.02.007

15. Brummelte S, Grunau RE, Zaidman-Zait A, Weinberg J, Nordstokke D, Cepeda IL. Cortisol levels in relation to maternal interaction and child internalizing behavior in preterm and full-term children at 18 months corrected age. Dev Psychobiol (2011) 53:184-95. doi:10.1002/dev.20511

16. Graven SN. Early neurosensory visual development of the fetus and newborn. Clin Perinatol (2004) 31:199-216. doi:10.1016/j.clp.2004.04.010

17. Mörelius E, Hellström-Westas L, Carlén C, Norman E, Nelson N. Is a nappy change stressful to neonates? Early Hum Dev (2006) 82:669-76. doi:10.1016/j. earlhumdev.2005.12.013

18. Grunau RE, Whitfield MF, Petrie-Thomas J, Synnes AR, Cepeda IL, Keidar A, et al. Neonatal pain, parenting stress and interaction, in relation to cognitive and motor development at 8 and 18 months in preterm infants. Pain (2009) 143:138-46. doi:10.1016/j.pain.2009.02.014

19. Klein VC, Gaspardo CM, Martinez FE, Grunau RE, Linhares MBM. Pain and distress reactivity and recovery as early predictors of temperament in toddlers born preterm. Early Hum Dev (2009) 85:569-76. doi:10.1016/j. earlhumdev.2009.06.001

20. Smith GC, Gutovich J, Smyser C, Pineda R, Newnham C, Tjoeng TH, et al. Neonatal intensive care unit stress is associated with brain development in preterm infants. Ann Neurol (2011) 70:541-9. doi:10.1002/ana.22545

21. Zwicker JG, Grunau RE, Adams E, Chau V, Brant R, Poskitt KJ, et al. Score for neonatal acute physiology-II and neonatal pain predict Corticospinal tract development in premature newborns. Pediatr Neurol (2013) 48:123-9. doi:10.1016/j.pediatrneurol.2012.10.016

22. Ranger M, Synnes AR, Vinall J, Grunau RE. Internalizing behaviours in school-age children born very preterm are predicted by neonatal pain and morphine exposure. Eur J Pain (2014) 18:844-52. doi:10.1002/j.1532-2149. 2013.00431.x

23. Provenzi L, Giusti L, Fumagalli M, Tasca H, Ciceri F, Menozzi G, et al. Pain-related stress in the neonatal intensive care unit and salivary cortisol reactivity to socio-emotional stress in 3-month-old very preterm infants. Psychoneuroendocrinology (2016) 72:161-5. doi:10.1016/j.psyneuen.2016. 07.010

24. Latva R, Lehtonen L, Salmelin RK, Tamminen T. Visiting less than every day: a marker for later behavioral problems in Finnish preterm infants. Arch Pediatr Adolesc Med (2004) 158:1153-7. doi:10.1001/archpedi.158.12.1153

25. Mörelius E, Nelson N, Gustafsson PA. Salivary cortisol response in motherinfant dyads at high psychosocial risk. Child Care Health Dev (2007) 33:128-36. doi:10.1111/j.1365-2214.2006.00637.x

26. Als H, Duffy FH, McAnulty GB, Rivkin MJ, Vajapeyam S, Mulkern RV, et al. Early experience alters brain function and structure. Pediatrics (2004) 113:846-57. doi:10.1542/peds.113.4.846 
27. Westrup B. Newborn individualized developmental care and assessment program (NIDCAP) - family-centered developmentally supportive care. Early Hum Dev (2007) 83:443-9. doi:10.1016/j.earlhumdev.2007.03.006

28. Altimier L, Kenner C, Damus K. The wee care neuroprotective NICU program (wee care): the effect of a comprehensive developmental care training program on seven neuroprotective core measures for family-centered developmental care of premature neonates. Newborn Infant Nurs Rev (2015) 15:6-16. doi:10.1053/j.nainr.2015.01.006

29. Montirosso R, Del Prete A, Bellu R, Tronick EE, Borgatti R; Neonatal Adequate Care for Quality of Life (NEO-ACQUA) Study Group. Level of NICU quality of developmental care and neurobehavioral performance in very preterm infants. Pediatrics (2012) 129:e1129-37. doi:10.1542/peds.2011-0813

30. Montirosso R, Casini E, Del Prete A, Zanini R, Bellù R, Borgatti R, et al. Neonatal developmental care in infant pain management and internalizing behaviours at 18 months in prematurely born children. Eur J Pain (2016) 20:1010-21. doi:10.1002/ejp.826

31. Montirosso R, Giusti L, Del Prete A, Zanini R, Bellù R, Borgatti R, et al. Language outcomes at 36 months in prematurely born children is associated with the quality of developmental care in NICUs. J Perinatol (2016) 36:768-74. doi:10.1038/jp.2016.57

32. Cong X, Ludington-Hoe SM, Walsh S. Randomized crossover trial of kangaroo care to reduce biobehavioral pain responses in preterm infants: a pilot study. Biol Res Nurs (2011) 13:204-16. doi:10.1177/1099800410385839

33. Calciolari G, Montirosso R. The sleep protection in the preterm infants. $J$ Matern Fetal Neonatal Med (2011) 24(1):12-4. doi:10.3109/14767058.2011. 607563

34. Scher MS, Ludington-Hoe S, Kaffashi F, Johnson MW, Holditch-Davis D, Loparo KA. Neurophysiologic assessment of brain maturation after an 8-week trial of skin-to-skin contact on preterm infants. Clin Neurophysiol (2009) 120:1812-8. doi:10.1016/j.clinph.2009.08.004

35. Feldman R, Rosenthal Z, Eidelman AI. Maternal-preterm skin-to-skin contact enhances child physiologic organization and cognitive control across the first 10 years of life. Biol Psychiatry (2014) 75:56-64. doi:10.1016/j. biopsych.2013.08.012

36. Provenzi L, Guida E, Montirosso R. Preterm behavioral epigenetics: a systematic review. Neurosci Biobehav Rev (2017). doi:10.1016/j.neubiorev.2017. 08.020

37. Chau CMY, Ranger M, Sulistyoningrum D, Devlin AM, Oberlander TF, Grunau RE. Neonatal pain and COMT Val158Met genotype in relation to serotonin transporter (SLC6A4) promoter methylation in very preterm children at school age. Front Behav Neurosci (2014) 8:409. doi:10.3389/ fnbeh.2014.00409

38. Provenzi L, Fumagalli M, Sirgiovanni I, Giorda R, Pozzoli U, Morandi F, et al. Pain-related stress during the neonatal intensive care unit stay and SLC6A4 methylation in very preterm infants. Front Behav Neurosci (2015) 9:99. doi:10.3389/fnbeh.2015.00099

39. Montirosso R, Provenzi L, Giorda R, Fumagalli M, Morandi F, Sirgiovanni I, et al. SLC6A4 promoter region methylation and socio-emotional stress response in very preterm and full-term infants. Epigenomics (2016) 8:895-907. doi:10.2217/epi-2016-0010

40. Montirosso R, Provenzi L, Fumagalli M, Sirgiovanni I, Giorda R, Pozzoli U, et al. Serotonin transporter gene (SLC6A4) methylation associates with neonatal intensive care unit stay and 3-month-old temperament in preterm infants. Child Dev (2016) 87(1):38-48. doi:10.1111/cdev.12492

41. Koliada AK, Krasnenkov DS, Vaiserman AM. Telomeric aging: mitotic clock or stress indicator? Front Genet (2015) 6:82. doi:10.3389/fgene.2015.00082

42. Blackburn EH, Epel ES. Telomeres and adversity: too toxic to ignore. Nature (2012) 490:169-71. doi:10.1038/490169a

43. Aviv A, Chen W, Gardner JP, Kimura M, Brimacombe M, Cao X, et al. Leukocyte telomere dynamics: longitudinal findings among young adults in the Bogalusa heart study. Am J Epidemiol (2008) 169:323-9. doi:10.1093/aje/ kwn338

44. Lin J, Epel E, Cheon J, Kroenke C, Sinclair E, Bigos M, et al. Analyses and comparisons of telomerase activity and telomere length in human $\mathrm{T}$ and B cells: insights for epidemiology of telomere maintenance. J Immunol Methods (2010) 352:71-80. doi:10.1016/j.jim.2009.09.012

45. Chan SR, Blackburn EH. Telomeres and telomerase. Philos Trans R Soc Lond B Biol Sci (2004) 359:109-21. doi:10.1098/rstb.2003.1370
46. Mather KA, Jorm AF, Parslow RA, Christensen H. Is telomere length a biomarker of aging? A review. J Gerontol A Biol Sci Med Sci (2011) 66:202-13. doi:10.1093/gerona/glq180

47. Martin-Gronert MS, Tarry-Adkins JL, Cripps RL, Chen J-H, Ozanne SE. Maternal protein restriction leads to early life alterations in the expression of key molecules involved in the aging process in rat offspring. Am J Physiol Regul Integr Comp Physiol (2007) 294:R494-500. doi:10.1152/ajpregu.00530.2007

48. Haussmann MF, Salomons HM, Verhulst S. Telomere measurement tools: telometric produces biased estimates of telomere length. Heredity (2011) 107:371-371. doi:10.1038/hdy.2011.10

49. Epel ES, Blackburn EH, Lin J, Dhabhar FS, Adler NE, Morrow JD, et al. Accelerated telomere shortening in response to life stress. Proc Natl Acad Sci U S A (2004) 101:17312-5. doi:10.1073/pnas.0407162101

50. Parks CG, Miller DB, McCanlies EC, Cawthon RM, Andrew ME, DeRoo LA, et al. Telomere length, current perceived stress, and urinary stress hormones in women. Cancer Epidemiol Biomarkers Prev (2009) 18:551-60. doi:10.1158/1055-9965.EPI-08-0614

51. Damjanovic AK, Yang Y, Glaser R, Kiecolt-Glaser JK, Nguyen H, Laskowski B, et al. Accelerated telomere erosion is associated with a declining immune function of caregivers of Alzheimer's disease patients. J Immunol (2007) 179:4249-54. doi:10.4049/jimmunol.179.6.4249

52. Kiecolt-Glaser JK, Glaser R. Psychological stress, telomeres, and telomerase. Brain Behav Immun (2010) 24:529-30. doi:10.1016/j.bbi.2010.02.002

53. Entringer S, Epel ES, Kumsta R, Lin J, Hellhammer DH, Blackburn EH, et al. Stress exposure in intrauterine life is associated with shorter telomere length in young adulthood. Proc Natl Acad Sci U S A (2011) 108:E513-8. doi:10.1073/ pnas. 1107759108

54. Drury SS, Theall K, Gleason MM, Smyke AT, De Vivo I, Wong JYY, et al. Telomere length and early severe social deprivation: linking early adversity and cellular aging. Mol Psychiatry (2012) 17:719-27. doi:10.1038/mp.2011.53

55. Tyrka AR, Price LH, Kao H-T, Porton B, Marsella SA, Carpenter LL. Childhood maltreatment and telomere shortening: preliminary support for an effect of early stress on cellular aging. Biol Psychiatry (2010) 67:531-4. doi:10.1016/j. biopsych.2009.08.014

56. Kiecolt-Glaser JK, Gouin J-P, Weng N, Malarkey WB, Beversdorf DQ, Glaser R. Childhood adversity heightens the impact of later-life caregiving stress on telomere length and inflammation. Psychosom Med (2011) 73:16-22. doi:10.1097/PSY.0b013e31820573b6

57. O'Donovan A, Pantell MS, Puterman E, Dhabhar FS, Blackburn EH, Yaffe K, et al. Cumulative inflammatory load is associated with short leukocyte telomere length in the health, aging and body composition study. PLoS One (2011) 6:e19687. doi:10.1371/journal.pone.0019687

58. Friedrich U, Schwab M, Griese EU, Fritz P, Klotz U. Telomeres in neonates: new insights in fetal hematopoiesis. Pediatr Res (2001) 49:252-6. doi:10.1203/00006450-200102000-00020

59. Holmes DK, Bellantuono I, Walkinshaw SA, Alfirevic Z, Johnston TA, Subhedar NV, et al. Telomere length dynamics differ in foetal and early post-natal human leukocytes in a longitudinal study. Biogerontology (2009) 10:279-84. doi:10.1007/s10522-008-9194-y

60. Menon R, Conneely KN, Smith AK. DNA methylation: an epigenetic risk factor in preterm birth. Reprod Sci (2012) 19:6-13. doi:10.1177/1933719111424446

61. Vasu V, Turner KJ, George S, Greenall J, Slijepcevic P, Griffin DK. Preterm infants have significantly longer telomeres than their term born counterparts. PLoS One (2017) 12:e0180082. doi:10.1371/journal.pone.0180082

62. Turner KJ, Vasu V, Greenall J, Griffin DK. Telomere length analysis and preterm infant health: the importance of assay design in the search for novel biomarkers. Biomark Med (2014) 8:485-98. doi:10.2217/bmm.14.13

63. Greisen G, Mirante N, Haumont D, Pierrat V, Pallás-Alonso CR, Warren I, et al. Parents, siblings and grandparents in the neonatal intensive care unit A survey of policies in eight European countries. Acta Paediatr (2009) 98:1744-50. doi:10.1111/j.1651-2227.2009.01439.x

64. Provenzi L, Barello S. Behavioral epigenetics of family-centered care in the neonatal intensive care unit. JAMA Pediatr (2015) 169(7):697-8. doi:10.1001/ jamapediatrics.2015.0367

65. Montirosso R, Tronick E, Borgatti R. Promoting neuroprotective care in neonatal intensive care units and preterm infant development: insights from the neonatal adequate care for quality of life study. Child Dev Perspect (2017) 11:9-15. doi:10.1111/cdep.12208 
66. Shalev I. Early life stress and telomere length: investigating the connection and possible mechanisms. Bioessays (2012) 34:943-52. doi:10.1002/bies.201200084

67. Provenzi L, Borgatti R, Montirosso R. Why are prospective longitudinal studies needed in preterm behavioral epigenetic research? - Reply. JAMA Pediatr (2017) 171:92. doi:10.1001/jamapediatrics.2016.2467

68. Nettle D, Monaghan P, Gillespie R, Brilot B, Bedford T, Bateson M. An experimental demonstration that early-life competitive disadvantage accelerates telomere loss. Proc Biol Sci (2014) 282:20141610. doi:10.1098/ rspb.2014.1610

69. Kantake M, Yoshitake H, Ishikawa H, Araki Y, Shimizu T. Postnatal epigenetic modification of glucocorticoid receptor gene in preterm infants: a prospective cohort study. BMJ Open (2014) 4:e005318. doi:10.1136/bmjopen-2014-005318

70. Sibille KT, Witek-Janusek L, Mathews HL, Fillingim RB. Telomeres and epigenetics: potential relevance to chronic pain. Pain (2012) 153:1789-93. doi:10.1016/j.pain.2012.06.003

71. Gotlib IH, LeMoult J, Colich NL, Foland-Ross LC, Hallmayer J, Joormann J, et al. Telomere length and cortisol reactivity in children of depressed mothers. Mol Psychiatry (2015) 20:615-20. doi:10.1038/mp.2014.119
72. Sjogren P, Fisher R, Kallings L, Svenson U, Roos G, Hellenius ML. Stand up for health-avoiding sedentary behaviour might lengthen your telomeres: secondary outcomes from a physical activity RCT in older people. Br J Sport Med (2014) 48(19):1407-9. doi:10.1136/bjsports-2013-093342

73. Provenzi L, Montirosso R. Document Epigenethics in the neonatal intensive care unit: conveying complexity in health care for preterm children. JAMA Pediatr (2015) 169(7):617-8. doi:10.1001/jamapediatrics.2015.43

Conflict of Interest Statement: The authors declare that the research was conducted in the absence of any commercial or financial relationships that could be construed as a potential conflict of interest.

Copyright (C) 2017 Provenzi, Scotto di Minico, Giorda and Montirosso. This is an openaccess article distributed under the terms of the Creative Commons Attribution License (CC BY). The use, distribution or reproduction in other forums is permitted, provided the original author(s) or licensor are credited and that the original publication in this journal is cited, in accordance with accepted academic practice. No use, distribution or reproduction is permitted which does not comply with these terms. 